九州大学学術情報リポジトリ

Kyushu University Institutional Repository

\title{
Ultrastructure of Oogenesis in the Adult Cattle Tick, Haemaphysalis longicornis
}

Yano, Yasuhiro

Zoological Laboratory, Faculty of Agriculture, Kyushu University

Mori, Takayuki

Zoological Laboratory, Faculty of Agriculture, Kyushu University

Shiraishi, Satoshi

Zoological Laboratory, Faculty of Agriculture, Kyushu University

Uchida, Teruaki

Zoological Laboratory, Faculty of Agriculture, Kyushu University

https://doi.org/10.5109/23888

出版情報: 九州大学大学院農学研究院紀要. 34 (1/2)，pp.53-67，1989-11. Kyushu University バージョン：

権利関係 : 


\title{
Ultrastructure of Oogenesis in the Adult Cattle Tick, Haemaphysalis longicornis*
}

\author{
Yasuhiro Yano ${ }^{\dagger}$, Takayuki Mōri, Satoshi Shiraishi \\ and Teru Aki Uchida
}

\author{
Zoological Laboratory, Faculty of Agriculture, Kyushu \\ University 46-06, Fukuoka 812, Japan
}

(Received May 10, 1989)

\begin{abstract}
The oocyte development during the period from the unfed stage to the day of oviposition, morphological changes of funicle cells at ovulation, and situation of spermatozoa in the ovarian lumen were examined in bisexual Haemaphyalis longicornis. The oocyte began to develop with feeding, protruded into the haemocoel from the surface of the ovary, and then became sustained by the funicle cells derived from ovarian epithelial cells. Yolk deposition and egg-shell synthesis commenced on the day of detachment. During vitellogenesis, the large oocyte nucleus became situated near the side of the funicle cells, numerous electron dense granules accumulated in the perinuclear zone of the cytoplasm, and well-developed microvilli and active micropinocytosis were conspicuous on the oocyte plasma membrane. Upon completion of the oocyte development, the well-developed funicle cells directly faced to the ovarian lumen and formed complicated infoldings of the plasma membrane in order to allow mature oocytes to easily pass through a pathway among them into the lumen. Many spermatozoa ascended to the ovarian lumen on the oviposition day, some of them were in contact with microvilli of the ovarian epithelial cells and some resided in indentations on the plasma membrane of the funicle cells. A spermatozoon seemed to fertilize the ovulated oocytes in the ovarian lumen, because they had not a large, characteristic egg nucleus any longer.
\end{abstract}

\section{INTRODUCTION}

Haemaphysalis Iongicornis is widely distributed in Australia, New Zealand, New Caledonia, Fiji, Japan, Korea, and northeastern China and USSR, having parthenogenetic and bisexual races (Hoogstraal et al., 1968). In Japan, where both races occur, this species is of economic importance as the most dominant tick in pastures and as the vector of Theileria sergenti, causing theileriosis among cattle.

Tick oogenesis has been recently reviewed, being classified ultrastructurally into the following three stages, i. e. previtellogenic, vitellogenic and ovulatory stage (Diehl et al., 1982). Details of ovulation and fertilization in ticks have not been sufficiently elucidated. Within the genus Haemaphysalis, there have been a few studies on the anatomy of H. Alava (Saito, 1960), the histochemistry of the genital organs in H . spinigera (Chinery, 1965) and the ultrastructure on penetrating stages of Babesia major

\footnotetext{
* Reprint requests to the third author.

† Present address : Department of Immunology and Parasitology, Fukui Medical School, Matsuoka, Fukui' 910-11, Japan.
} 
infecting the ovary of H. punctata (Morzaria et al., 1977). In H. Zongicornis, however, very few data are available on the ultrastructure of oogenesis, although the ovarian development has been examined with the light microscope in the parthenogenetic female from Australia (Khalil, 1972).

The purpose of the present study is to examine with the electron microscope the oocyte development and ovulation, morphological changes of funicle cells and situations of spermatozoa in the ovarian lumen in the bisexual female of $H$. Zongicornis, and to discuss the characteristics of oogenesis, the mechanism of ovulation and the site of fertilization in ticks.

\section{MATERIALS AND METHODS}

Unfed female and male ticks of H.longicornis were collected by dragging on a pasture at the Kujū highland, Öita Prefecture ; they were reared on the ears of a domestic rabbit at the same time in the laboratory, and then each ear was covered with a cotton bag. The females which detached into the bag after engorgement were put in plastic cases with a wet filter papers, and allowed to oviposit in a constantly dark incubator kept at $25^{\circ} \mathrm{C}$.

The ovary was dissected out in a cold 3\% glutaraldehyde in 0.2 M-phosphate buffer ( $\mathrm{pH} 7.4$ ), fixed with the same fixative for 6 hours, and then washed thoroughly in the same buffer ; the tissue was post-fixed with $1 \%$ osmium tetroxide in the same buffer, dehydrated with acetone and embedded in epoxy resin. Thick sections (ca. 1 $\mu \mathrm{m}$ ) for light microscopy were stained with toluidine blue. Thin sections (ca. $60 \mathrm{~nm}$ ) for electron microscopy were doubly stained with uranyl and lead acetate before examination in an Hitachi HS-9 electron microscope $(75 \mathrm{kV})$.

\section{RESULTS}

To bring about a better understanding, the relationships between the state of the ticks and changes both in the body volume of the females during feeding based on the data by Yano et $a l$. (1989) and in the diameter of oocytes from the unfed stage to the day of oviposition are shown in Fig. 1. The typical female, which mated with a male on 4th day in feeding, engorged and detached from the host on the 6th day. The oocyte rapidly increased in size from the day of detachment, and approximated to the size of the mature egg on the 4th day after detachment. The female commenced ovipositing on the 6th day after detachment. The morphological changes of the ovary and oocytes are described separately according to the following six states - unfed stage, 4th day in feeding, detachment day, 2nd day after detachment, 4th day after detachment and oviposition day.

\section{Unfed stage}

A large, round nucleus (diam. ca. $10 \mu \mathrm{m}$ ) with a distinct nucleolus was centrally located in the oocyte (diam. ca. $20 \mu \mathrm{m}$ ) (Fig. 2, inset a). The oocyte contained free ribosomes throughout the cytoplasm and massive round mitochondria in parts : both the oocyte and the ovarian epithelial cell faced to the haemocoel through the basement membrane (Fig. 2 and inset b). The intercellular bridge between the oocytes had many 


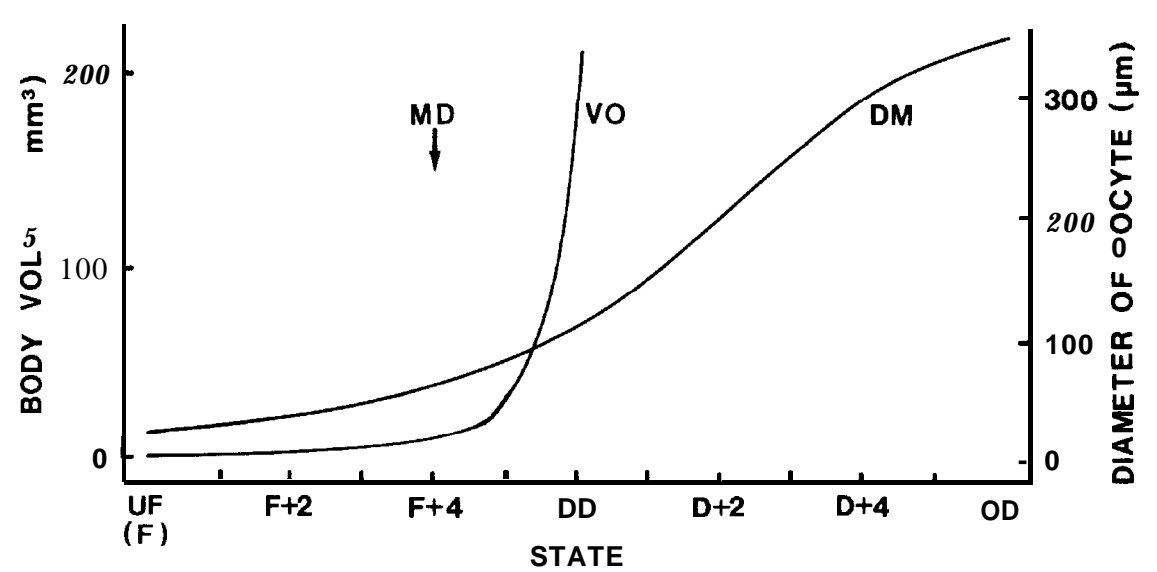

Fig. 1. Typical daily changes in the body volume (VO) and in the diameter of the oocyte (DM) according to the following states of female Haemaphysalis Iongicomis : $\mathrm{UF}$, unfed stage including the beginning day of feeding $(\mathrm{F}) ; \mathrm{F}+1$ to $F+5$, days in feeding ; DD, detachment day, $\mathrm{D}+1$ to $\mathrm{D}+5$, days after detachment ; OD, oviposition day. MD, mating day.

tubular invaginations of the plasma membrane near the bridge, processes of the ovarian epithelial cells went between the oocytes, and the apposed plasma membranes of both the cells were smoothly parallel with each other without an intercellular junctional complex (Fig. 3).

\section{Fourth day in feeding}

The oocytes (diam. ca. $60 \mu \mathrm{m}$ ) began to protrude into the haemocoel from the surface of the ovary, and then became maintained by the undeveloped funicle cells derived from the ovarian epithelial cells ; each had a large nucleus (diam. ca. $30 \mu \mathrm{m}$ ), surrounded by a distinct layer of the perinuclear zone, at the germinal vesicle stage (Fig. 4, inset). The cytoplasm contained numerous mitochondria, well-developed rough endoplasmic reticulum and the Golgi complex. Great quantities of electron-dense granules passing through the nuclear pores accumulated in the perinuclear zone of the cytoplasm, and were associated with masses of mitochondria (Figs. 4 and 5). Clubshaped microvilli began to protrude from the oocyte plasma membrane, the tops of which were reaching to the basement membrane (Fig. 6).

Undeveloped, cuboidal funicle cells had a large nucleus and scanty cytoplasm (ca. $10 \mu \mathrm{m}$ in height) with massive glycogen particles (Fig. 7). The oocyte and the funicle cells attached to one another with the microvilli, both of which had numerous vesicles in their boundary zone (Fig. 7, inset). The pairs of smoothly apposed plasma membranes of adjacent funicle cells run parallel to each other, and were connected with by the zonula adherens in parts (Fig. 8). The ovarian lurninal surface of the funicle cells was in contact with the flattened ovarian epithelial cells, and did not directly face to the ovarian lumen (Fig. 9). 


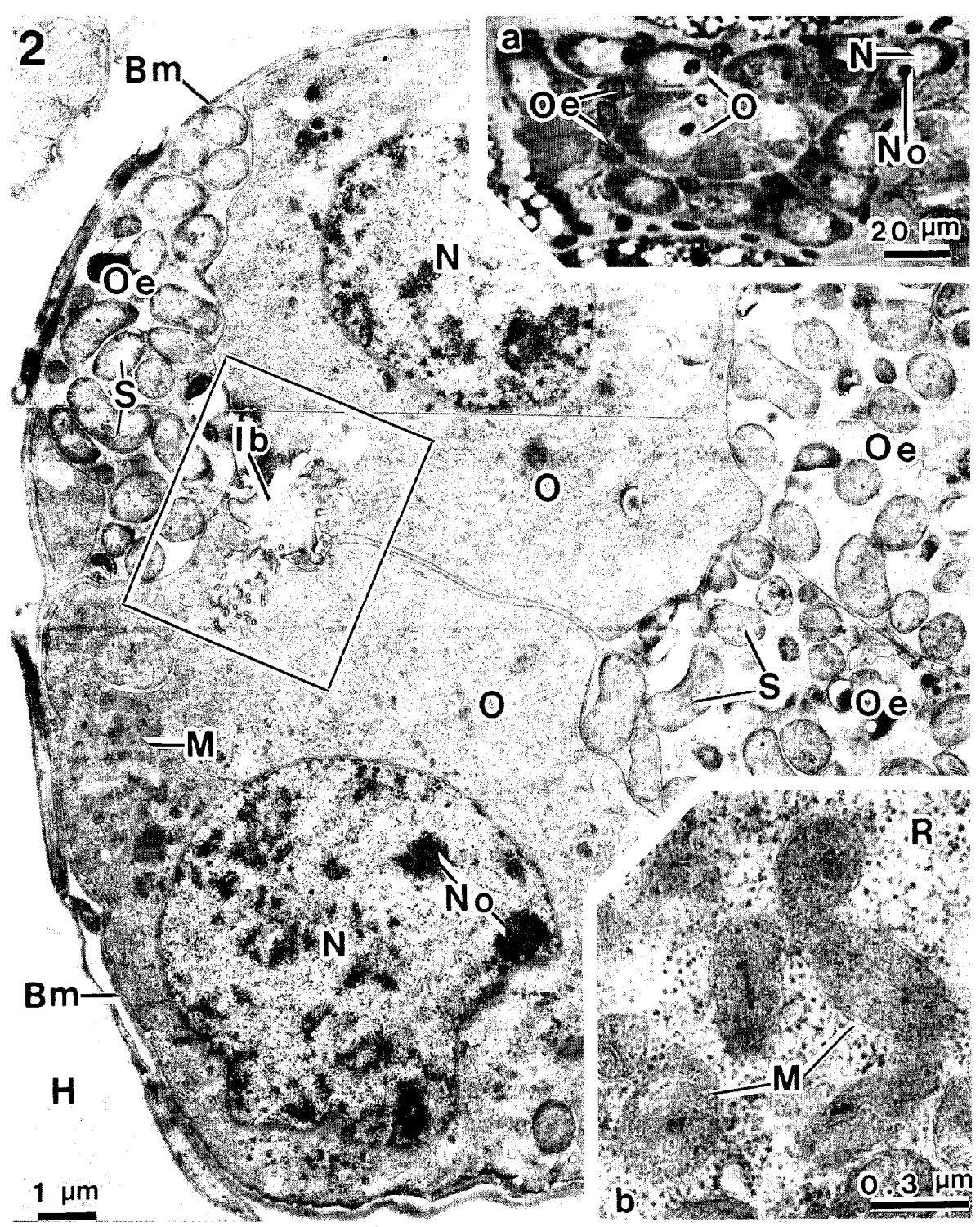

Fig. 2. Electron micrograph showing ovarian oocytes (0) connected with each other by an intercellular bridge ( $\mathrm{I}$ b, in the rectangle) and ovarian epithelial cells (Oe) which are occupied by numerous symbionts $(S)$ in the unfed stage. Inset a : light micrograph showing the ovary in the same stage. Inset $\mathrm{b}$ : electron micrograph showing part of the oocyte with a large quantity of ribosomes $(\mathrm{R})$ and masses of mitochondria $(\mathrm{M})$ in the cytoplasm at higher magnification. Bm, basement membrance; $\mathrm{H}$, haemocoel ; $\mathrm{N}$, nucleus ; No, nucleolus. 


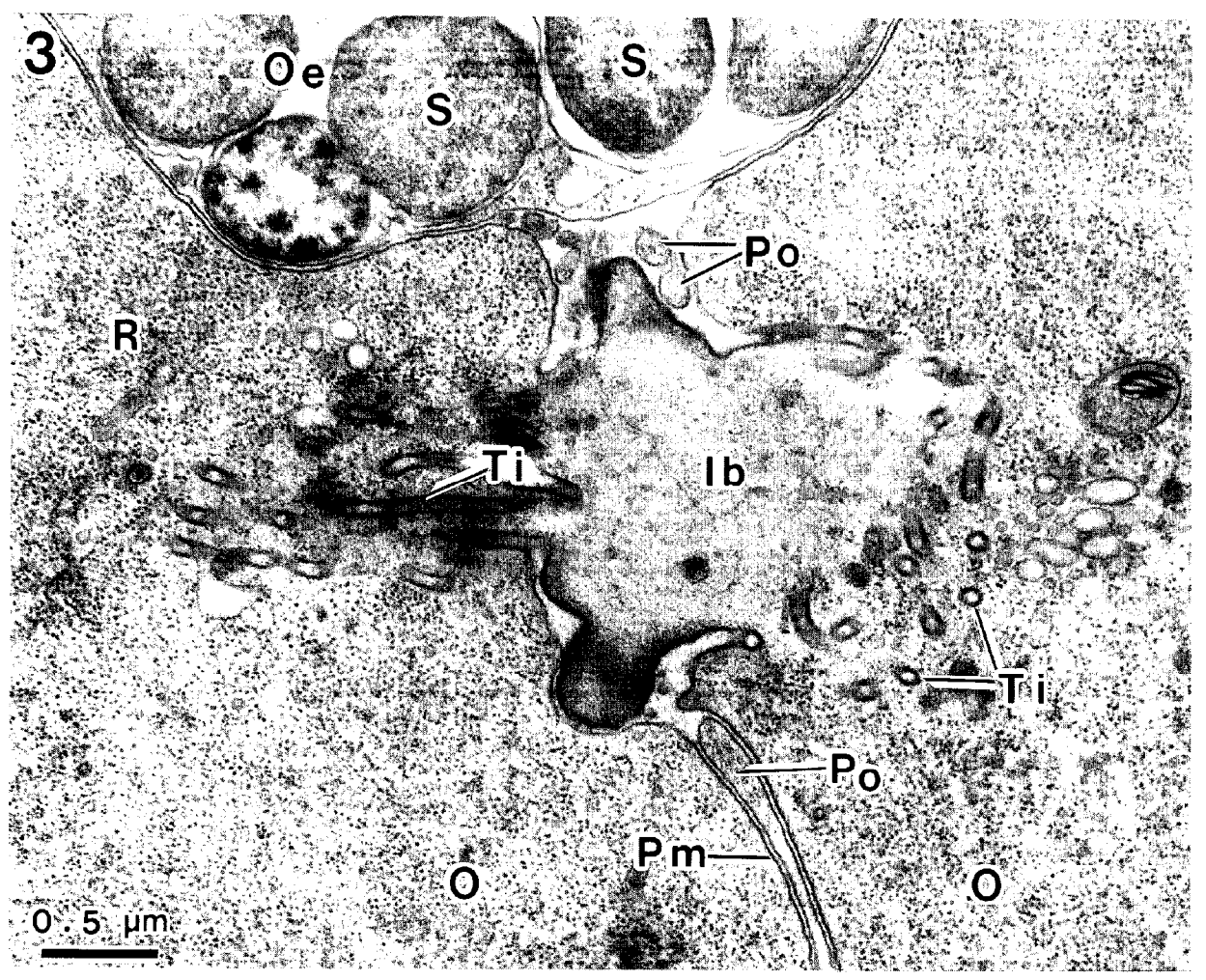

Fig. 3. Electron micrograph of the area enclosed in the rectangle on Fig. 2 at higher magnification, showing an intercellular bridge $(\mathrm{I} b)$ between oocytes $(\mathrm{O})$, which is accompanied with tubular invaginations (Ti) of the plasma membrane $(\mathrm{Pm})$, in the unfed stage. Oe, ovarian epithelial cell ; Po, process of ovarian epithelial cell ; R, ribosome ; $\mathrm{S}$, symbiont.

\section{D etachment day}

The oocyte developed further (diam. ca. $100 \mu \mathrm{m}$ ), the large nucleus moved to the side of the funicle cells (Fig. 10, inset), and numerous small yolk granules, together with lipid droplets and glycogen granules appeared for the first time (Fig. 10). Egg-shell precursors began to be produced in the gap between the oocyte and the basement menbrane ; coated pits and coated vesicles (diam. ca. $0.1 \mu \mathrm{m}$ ) were conspicuous on the oocyte plasma membrane at the base of elongated microvilli (Fig. 11). Multivesicular bodies (diam. 0.2-0.5 $\mu \mathrm{m}$ ), in which small vesicles gradually fused with one another, lost their internal membranes and became homogenous; their electrondensity increased, and consequently yolk granules were synthesized (Fig. 12 and inset).

\section{Second day after detachment}

Yolk granules with various sizes (maximum diam. ca. $35 \mu \mathrm{m}$ ) occupied most of the oocyte cytoplasm (diam. ca. $200 \mu \mathrm{m}$ ) (Fig. 13, inset). The egg-shell became thick (1.4 $\mu \mathrm{m})$, and was perforated by microvilli reaching to the basement membrane (Fig. 13). 

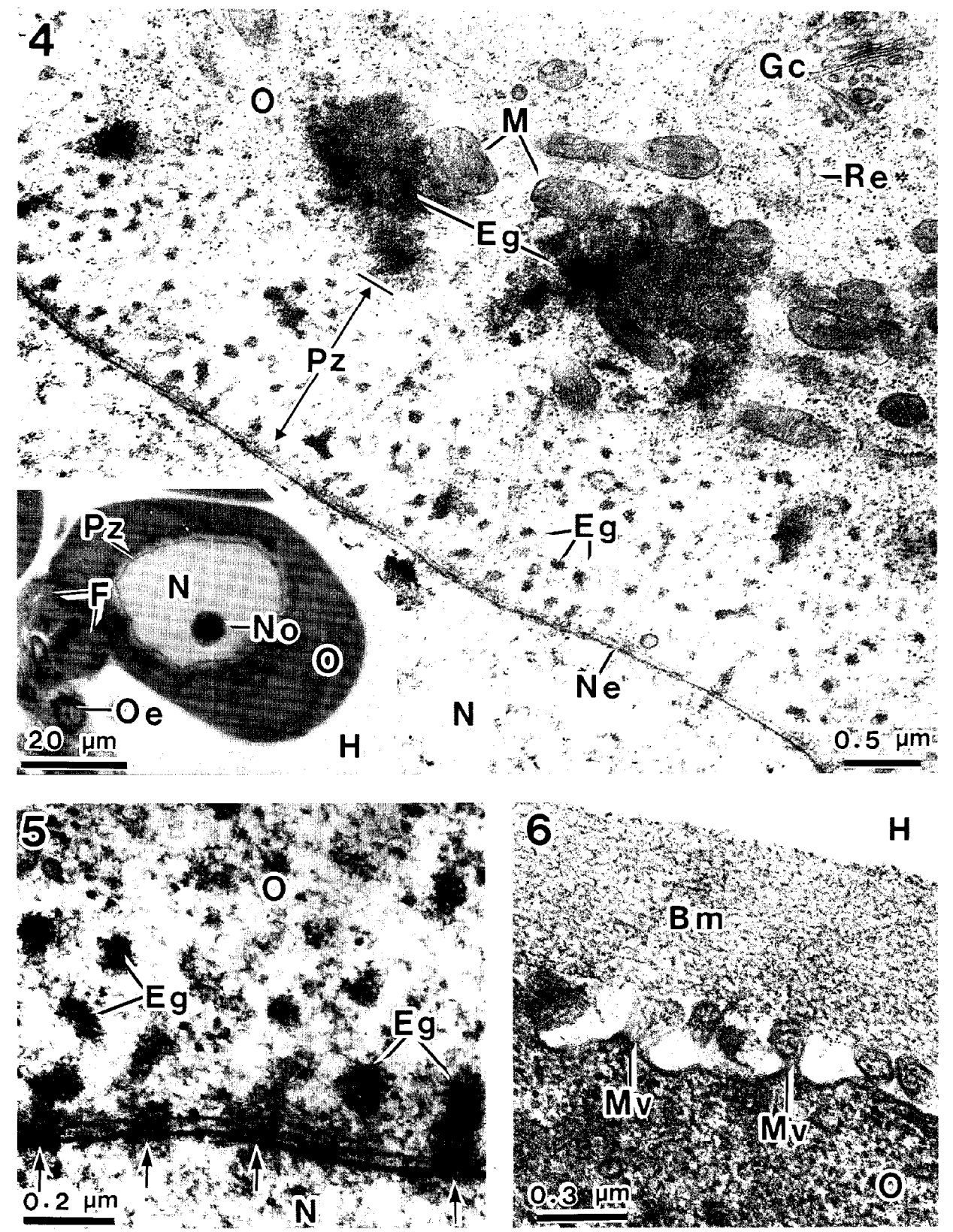

Fig. 4. Electron micrograph showing a perinuclear zone $(\mathrm{Pz})$ of an oocyte $(\mathrm{O})$, where numerous electron-dense granules $(\mathrm{Eg})$ are accumulated, on the 4th day in feeding. Inset : light micrograph of an oocyte (0) protruding into the haemocoel $(\mathrm{H})$ and undeveloped funicle cells $(\mathrm{F})$ derived from ovarian epithelial cells (Oe). Gc, Golgi 


\section{Fourth day after detachment}

Egg-shell synthesis and vitellogenesis were nearly completed. Spherical yolk granules became polygonal. The nuclear envelope was concaved together with the oocyte plasma membrane at the side of the funicle cells, and formed a large nuclear crypt (diam. ca. $20 \mu \mathrm{m}$ ) beneath the egg-shell (Fig. 14). The microvilli were being retracted through egg-shell slits (diam. ca. $0.1 \mu \mathrm{m}$ ). As a result, the interchorionic space (ca. $0.5 \mu \mathrm{m}$ in width) was formed between the oocyte and the egg-shell (Fig. 15).

\section{Oviposition day}

At this time, the ovary contained oocytes in all the developmental stages mentioned above, and some mature oocytes (diam. ca. $350 \mu \mathrm{m}$ ) were ovulated into the ovarian lumen. In spite of careful observations, the nucleus of the ovulated oocytes was not confirmed. Many spermatozoa ascending to the ovarian lumen were in close contact with microvilli of the ovarian epithelial cells (Fig. 16 and inset).

The mature oocyte just before ovulation was sustained by 20-30 columnar funicle cells (ca. $25 \mu \mathrm{m}$ in height) arranged in a monolayer but in two lines; they were poor in cell organelles, exposed one end to the egg-shell and the opposite end to the ovarian lumen. Some spermatozoa resided in indentations on the plasma membrane of the funicle cells (Fig. 17). The apposed plasma membranes of the adjacent funicle cells formed intensive infoldings, where zonula adherens accompanied with numerous filaments were conspicuous (Fig. 18). At postovulation, the basement membrane remained collapsed near the worn-out funicle cells (Fig. 19).

\section{DISCUSSION}

\section{Oocyte development in ticks}

Tick oogenesis has been classified into five stages on the basis of the morphological features of oocytes in Argas persicus, Hyalomma asiaticum and Ixodes ricinus (Balashov, 1972). The developmental stages of oocytes in bisexual H.longicornis were equivalent to Balashov's stages as follows : the oocytes in the unfed stage, on the 4th day in feeding and on the detachment day corresponded to that in Balashov's stage I (the period of small cytoplasmic growth), II (the period of great cytoplasmic growth) and III (the period of yolk deposition) respectively ; the oocyte on the 2nd day after detachment was ranked between Balashov's stages III and IV; further, the oocytes on the 4th day after detachment and on the oviposition day each agreed with Balashov's stage IV one (completion of vitellogenesis) and stage V one (after ovulation). The present study revealed for the first time the occurrence of the nuclear crypt

complex ; M, mitochondrion ; N, nucleus ; Ne, nuclear envelope ; No, nucleolus ; Re, rough endoplasmic reticulum.

Fig. 5. Electron micrograph of a perinuclear zone of the same oocyte (0) as in Fig. 4, showing electron-dense granules (Eg) passing through nuclear pores (arrows) at higher magnification. $\mathrm{N}$, nucleus.

Fig. 6. Electron micrograph showing formation of club-shaped microvilli (Mv) on the surface of an oocyte (0) on the 4 th day in feeding. Bm, basement membrane; $\mathrm{H}$, haemocoel. 

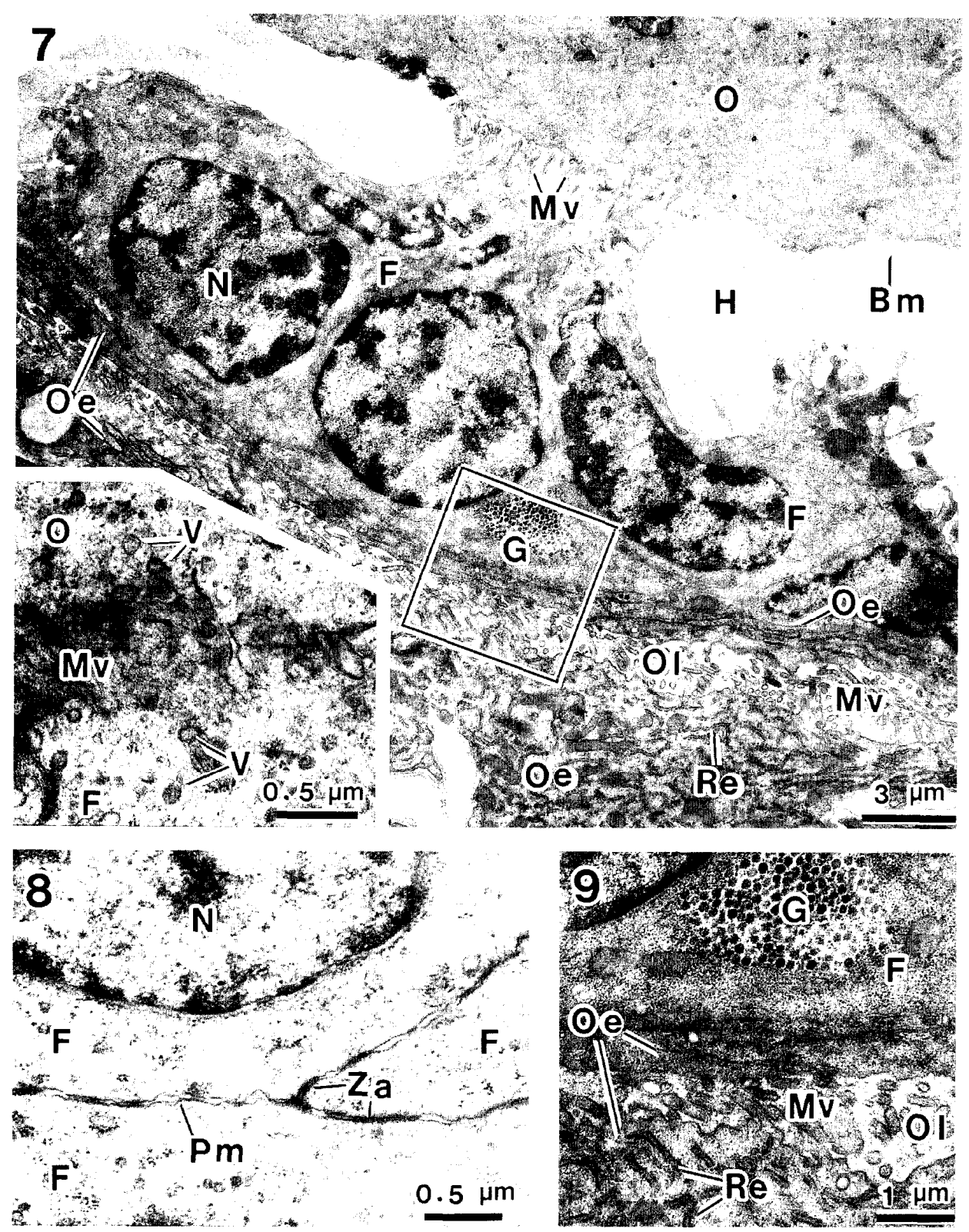

Fig. 7. Electron micrograph of undeveloped, cuboidal funicle cells $(\mathrm{F})$, showing their contact with an oocyte (0) and ovarian epithelial cells (Oe) (in the rectangle) on the opposite side, respectively, on the 4 th day in feeding. Inset : numerous vesicles (V) found inside a boundary zone between an oocyte $(0)$ and funicle cells $(\mathrm{F}) . \mathrm{Bm}$, basement membrane ; G, glycogen granule ; $\mathrm{H}$, haemocoel ; Mv, microvilli ; N, nucleus ; 01, ovarian lumen ; Re, rough endoplasmic reticulum. 
beneath the egg-shell of the oocyte on the 4th day after detachment, which may be associated with the mechanism of fertilization.

In Dermacentor andersoni, meiotic divisions have not been observed during any period of ovarian development in adult females (Brinton and Oliver, 1971a), and it has been thought that only oocytes are present in the females, because of additional enlargement and organellar differentiation of germinal cells, and especially the presence of their well-organized nucleoli (Brinton and Oliver, 1971b). Also in bisexual H. longicornis, the germinal cells in the unfed stage were the primary oocyte at the growth phase, which persisted until ovulation after detachment, because the nucleus stayed in the germinal vesicle stage and meiotic divisions did not occur during this course. On the other hand, in parthenogenetic H.longicornis, both a few oogonia (diam. 7.5 to $7.8 \mu \mathrm{m}$ ) and many primary oocytes (diam. 10 to $21 \mu \mathrm{m}$ ) occupy the ovary before the female feeds, and no further development occurs until female feeding (Khalil, 1972). Accordingly, further studies on such a difference in oogenesis between the bisexual and parthenogenetic races are needed.

Protein components of yolk granules in ticks originate from both exogenous and endogenous sources (Diehl et al., 1982). In Rhipicephalus sanguineus (Coons et al., 1982) and D. andersoni (Coons et al., 1986), fat body cells and mid gut cells synthesize exogenous vitellogenins. Biochemical and immunohistochemical data from Ornithodoros moubata demonstrate that the fat body is the site of vitellogenin synthesis (Chinzei and Yano, 1985), and vitellogenins, which are released into the haemocoel and then taken into the oocytes, become vitellins accounting for $80 \%$ of all the weights of oocyte proteins (Chinzei, 1983 ; 1986). An electron microscopic study on oogenesis in D. andersoni suggests that at least nuclear-nucleolar complexes, Golgi body, mitochondria and plasmalemma brush border contribute to yolk formation (Brinton and Oliver, 1971b). In the present study, the conspicuous development of microvilli and active micropinocytosis on the oocyte plasma membrane suggested intake of exogenous yolk protein precursors. Electron-dense granules accumulated in the perinuclear zone of the oocyte on the 4th day in feeding are presumably ribosomal precursors produced by the nucleus, and take part in synthesis of endogenous proteins as pointed out by Raikhel (1983).

\section{Mechanism of ovulation and sites of fertilization in ticks}

In bisexual H. longicornis, the ovarian luminal surface of the undeveloped funicle cells was in contact with ovarian epithelial cells. Upon completion of oocyte development, however, the funicle cells with scanty organelles became directly exposed to the ovarian lumen, owing to the retreat of the ovarian epithelial cells, when the welldeveloped funicle cells formed complicated infoldings of the plasma membrane. Such structural changes allow mature oocytes to pass easily through a pathway among the

Fig. 8. Electron micrograph showing intercellular junctions between funicle cells $(F)$ on the 4th day in feeding. N, nucleus ; Pm, plasma membrane ; Za, zonula adherens. Fig. 9. Electron micrograph of the area enclosed in the rectangle of Fig. 7 at higher magnification, showing contact of a funicle cell $(\mathrm{F})$ with a flattened ovarian epithelial cell (Oe). G, glycogen granule ; Mv, microvilli ; 01, ovarian lumen ; Re, rough endoplasmic reticulum. 

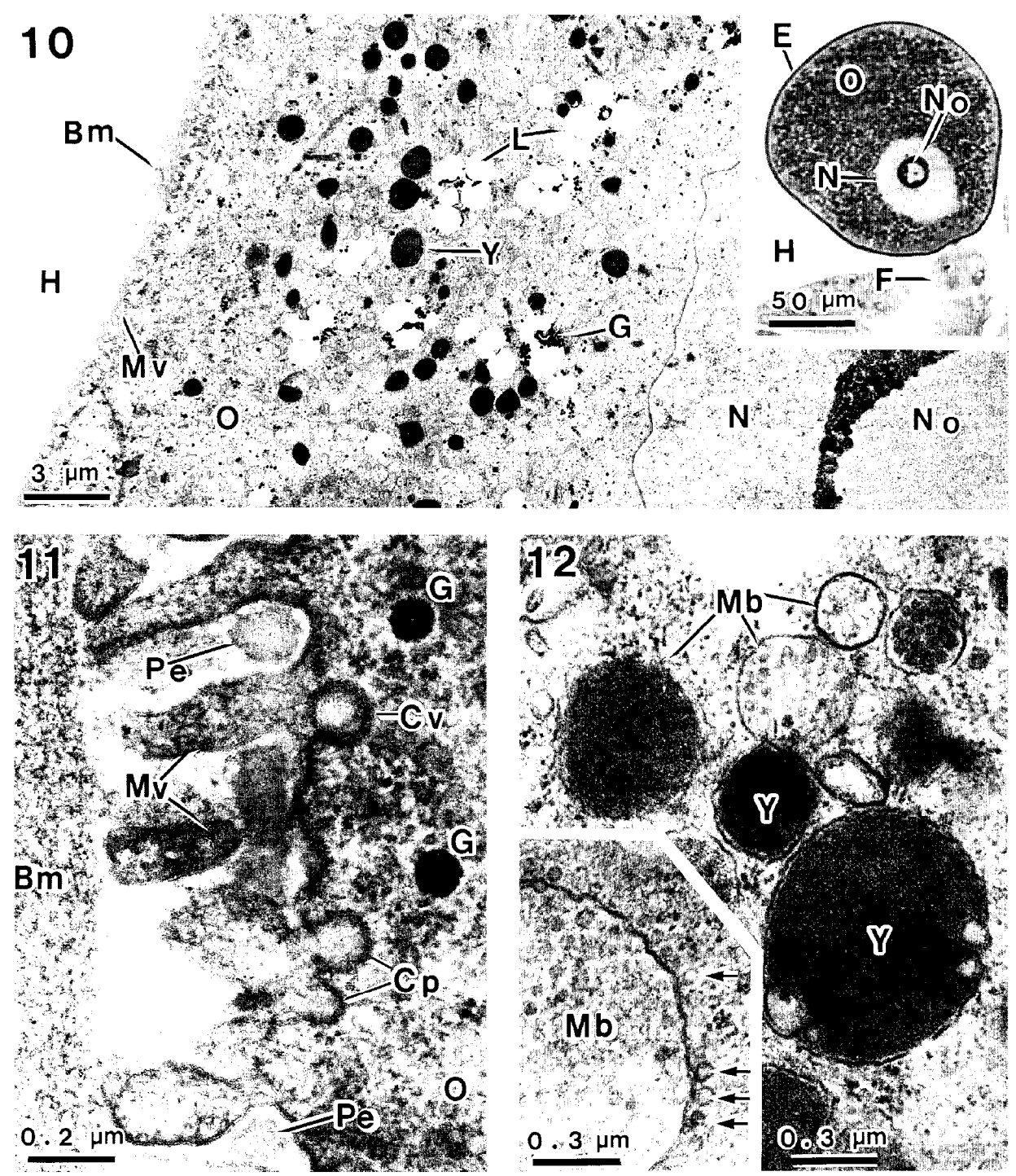

Fig. 10. Electron micrograph showing appearance of yolk granules (Y) in an oocyte (0) on the detachment day. Inset : light micrograph of a slightly advanced oocyte (0) on the same day. Bm, basement membrane ; E, egg-shell ; F, funicle cell ; G, glycogen granule ; H, haemocoel ; L, lipid droplet ; Mv, microvilli ; N, nucleus ; No, nucleolus. Fig. 11. Electron micrograph of the surface of the same oocyte (0) as in Fig. 10, showing well-developed microvilli $(\mathrm{Mv})$, coated pits $(\mathrm{Cp})$, coated vesicles $(\mathrm{Cv})$ and precursors of the egg-shell (Pe). Bm, basement membrane ; G, glycogen granule.

Fig. 12. Electron micrograph showing synthesis of yolk granules (Y) by fusion of internal vesicles in multivesicular bodies $(\mathrm{Mb})$ on'the detachment day. Inset : part of a multivesicular body ( $\mathrm{Mb}$ ) attached by many vesicles (arrows). 
funicle cells into the lumen, as in the so-called transition zone of $D$. andersoni (Brinton and Oliver, 1971b).

In $D$. andersoni, spermatozoa are present throughout the ovarian lumen from 3 days after completing engorgement to 24 hours after commencing oviposition (Brinton and Oliver, 1971a), and exhibit a propensity for active penetration of ovarian epithelial cells (Brinton et al., 1974). In H.longicornis, although spermatozoa did not yet ascend to the ovarian lumen on the 4th day after detachment, they reached there on the oviposition day, but seemed not to reach the egg-shell of ovarian oocytes.

At the present time, the actual site of fertilization in ticks is still a point of contention. There have been two opinions on this problem ; one is concerned with the oviduct and another the ovarian lumen (Oliver, 1974 ; Diehl et al., 1982). In this connection, it is yet uncertain in 0. moubata whether or not the condensed chromosomes in oocytes from the lower oviduct and the uterus are related to the process of fertilization (Diehl, 1970). In $H$. Zongicornis, ovulated oocytes had not a large, characteristic nucleus any longer. It is undeniable, therefore, that such a morphologically remarkable change was possibly caused by sperm penetration into the ovulated oocyte in the ovarian lumen.

\section{ACKNOWLEDGEMENTS}

The authors wish to express their hearty appreciation to the staff of Kujū Agricultural Research Center of Kyushu University for their kind help in collecting ticks ; Professor E. W. Jameson, Jr., University of California for comments on the manuscript. This work was supported in part by a Grant-in-Aid from the Ministry of Education, Science and Culture, Japan.

\section{REFERENCES}

Balashov, Y. S. 1972 Bloodsucking ticks (Ixodoidea) - Vectors of diseases of man and animals. Misc. Publ. Ent. Soc. Am., 8 : 161-376

Brinton, L. P., W. Burgdorfer and J. H. Oliver, Jr. 1974 Histology and fine structure of spermatozoa and egg passage in the female tract of Dermacentor andersoni Stiles (Atari-Ixodidae). Tissue \& Cell, 6: 109-125

Brinton, L. P. and J. H. Oliver, Jr. 1971a Gross anatomical, histological, and cytological aspects of ovarian development in Dermacentor andersoni Stiles (Acari : Ixodidae). J.Parasit., 57: 708-719

Brinton, L. P. and J. H. Oliver, Jr. 1971b Fine structure of oogonial and oocyte development in Dermacentor andersoni Stiles (Acari : Ixodidae). J. Parasit., $57:$ 720-747

Chinery, W. A. 1965 Studies on various glands of the tick Haemuphysalis spinigera Neumann 1897. ActaTrop., 22: 235-266

Chinzei, Y. 1983 Quantitative changes of vitellogenin and vitellin in adult female ticks, Omithodor. os moubata, during vitellogenesis. Mie. Med. J., 32 : 117-127

Chinzei, Y. 1986 Vitellogenin biosynthesis and processing in a soft tick, O mithodoros moubata. In "Host Regulated Developmental Mechanisms in Vector Arthropods", ed. by D. Borovsky and A. Spielman, University of Florida - IFAS, Florida Medical Entomology Laboratory, Vero Beach, pp. $18-24$

Chinzei, Y. and I. Yano 1985 Fat body is the site of vitellogenin synthesis in the soft tick, Ornithodoros moubata. J. Comp. Physiol., 155 : 671-678

Coons, L. B., R. Rosell-Davis and B. Tarnowski 1986 Bloodmeal digestion in ticks. In "Mor- 


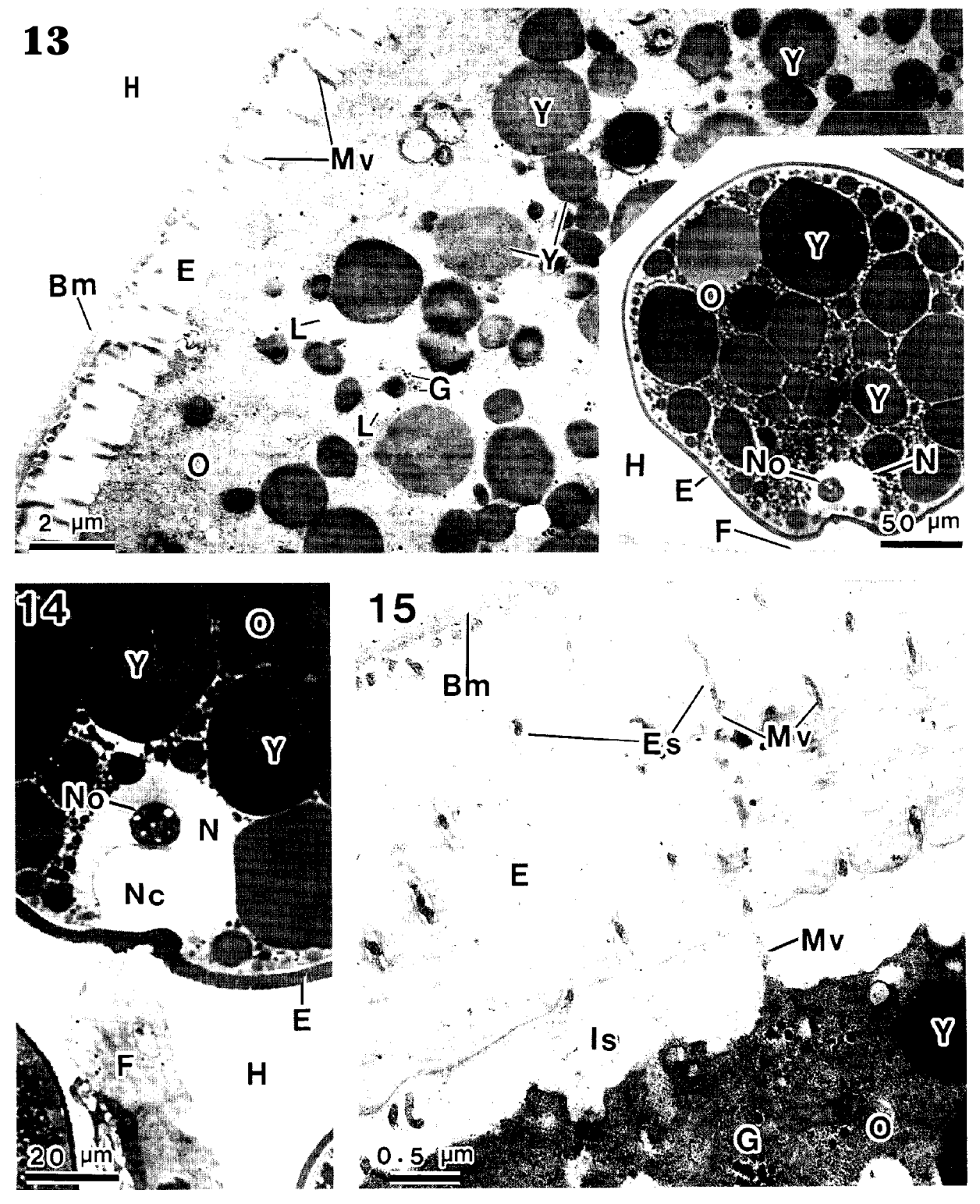




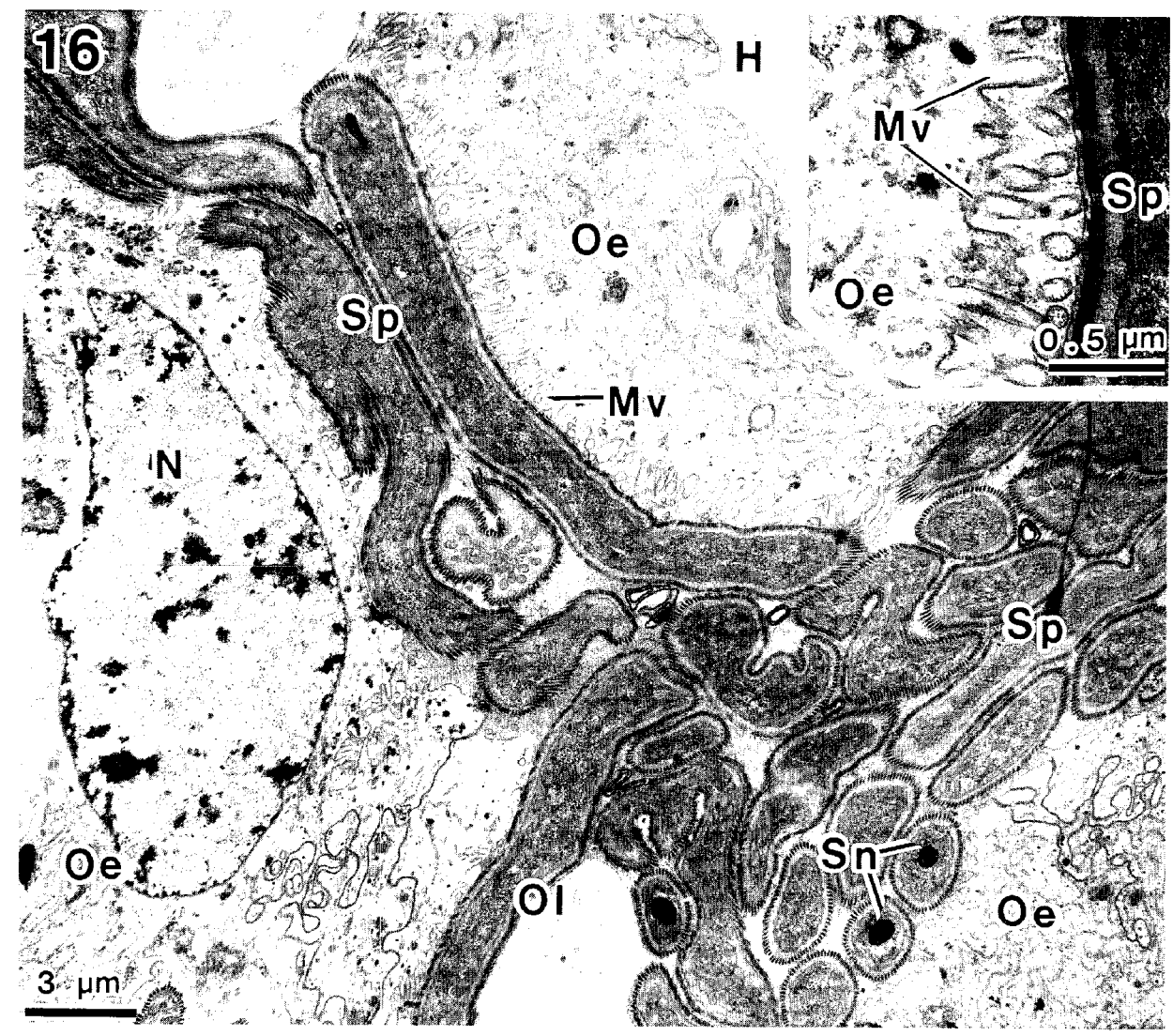

Fig. 16. Electron micrograph showing numerous spermatozoa (Sp) ascending to the ovarian lumen (01) on the oviposition day. Inset : electron micrograph showing a close relationship between an ovarian epithelial cell (Oe) and a spermatozoon at higher magnification. $\mathrm{H}$, haemocoel ; Mv, microvilli ; N, nucleus ; Sn, sperm nucleus.

Fig. 13. Electron micrograph of an oocyte (0) on the 2nd day after detachment, showing enlargement of yolk granules $(\mathrm{Y})$ and thickening of the egg-shell (E). Inset : light micrograph of an oocyte (0) on the same day as in Fig. 13. Bm, basement membrane ; F, funicle cell ; G, glycogen granule ; H, haemocoel ; L, lipid droplet ; Mv, microvilli ; N, nucleus ; No, nucleolus,

Fig. 14. Light micrograph showing a nuclear crypt $(\mathrm{NC})$ beneath the egg-shell $(\mathrm{E})$ in an oocyte $(0)$ on the 4 th day after detachment. F, funicle cell ; H, haemocoel ; N, nucleus ; No, nucleolus ; Y, yolk granule.

Fig. 15. Electron micrograph of the surface of an oocyte (0) on the same day as in Fig. 14, showing retraction of microvilli (Mv) and the interchorionic space ( I s) between the oocyte and the egg-shell (E). Bm, basement membrane ; Es, egg-shell slit ; G, glycogen granule ; Y, yolk granule. 


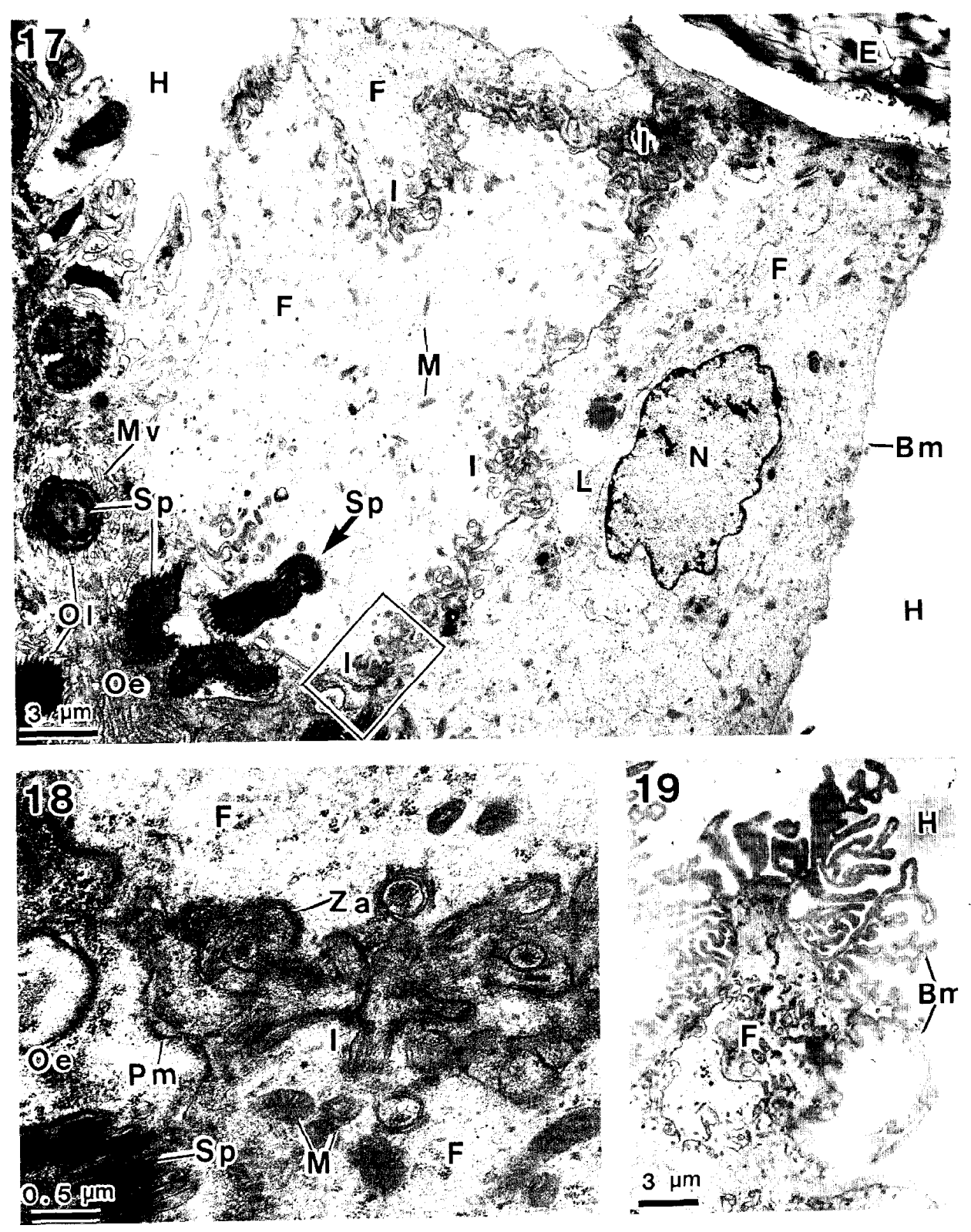


phology, Physiology, and Behavioral Biology of Ticks", ed. by J. R. Saure and J. A. Hair, Ellis Horwood Limited, Chichester, pp. 248-279

Coons, L. B., B. Tamowski and D. D. Ourth 1982 Rhipicephalus sanguineus : localization of vitellogenin synthesis by immunological methods and electron microscopy. Exp. Parasit., 54 : 331-339

Diehl, P. A. 1970 Zur Oogenese bei Ornithodoros moubata Murray (Ixodoidea : Argasidae) unter besonderer Berücksichtigung der Vitellogenese. ActaTrop., 2'7: 301-355

Diehl, P. A., A. Aeschlimann and F. D. Obenchain 1982 Tick reproduction : oogenesis and oviposition. In "Physiology of Ticks", ed. by F. D. Obenchain and R. Galun, Pergamon Press, Oxford, pp. 277-350

Hoogstraal, H., F. H. S. Roberts, G. M. Kohls and V. J. Tipton 1968 Review of Haemaphysalis (Kaiseriana) longicornis Neumann (resurrected) of Australia, New Zealand, New Caledonia, Fiji, Japan, Korea, and northeastern China and USSR, and its parthenogenetic and bisexual populations (Ixodoidea, Ixodidae). J. Parasit., 54 : 1197-1213

Khalil, G. M. 1972 Gonad development in the parthenogenetic Haemaphysalis (Kaiseriana) longicomis Neumann (Ixodoidea: Ixodidae). J.Parasit., 58: 817-823

Morzaria, S. P., P. Bland and D. W. Brocklesby 1977 The ultrastructure of penetrating stages of Babesia major infecting the ovary of Haemaphysalis punctata. Parasitology, 75 : 125-130

Oliver, J. H., Jr. 1974 Symposium of reproduction of arthropods of medical and veterinary importance. IV. Reproduction in ticks. J. Med. Ent., 11: 26-34

Raikhel, A. S. 1983 Chapter IX. Reproductive system. In "An Atlas of Ixodid Tick Ultrastructure", English publ. ed. by A. S. Raikhel and H. Hoogstraal, Special Publ. Ent. Soc. Am., pp. 221-239

Saito, Y. 1960 Studies on ixodid ticks. Part IV. The internal anatomy in each stage of Haemaphysalis flava Neumann, 1897. Acta Medica et Biologica, 8: 189-239

Yano, Y., S. Shiraishi and T. A. Uchida 1989 Feeding pattern, mating and oviposition in female Haemaphysalis longicornis. J.Fac. Agr., Kyushu U niv., 33: 287-296

Fig. 17. Electron micrograph of well-developed, columnar funicle cells $(\mathrm{F})$ bearing conspicuous infoldings ( $\mathrm{I}$, in the rectangle) of the plasma membranes, showing a spermatozoon ( $\mathrm{Sp}$, an arrow) residing in an indentation of the funicle plasma membrane on the oviposition day. Bm, basement membrane ; E, egg-shell ; H, haemocoel ; $\mathrm{M}$, mitochondrion ; Mv, microvilli ; L, lipid droplet ; N, nucleus ; Oe, ovarian epithelial cell ; 01, ovarian lumen.

Fig. 18. Electron micrograph of the area enclosed in the rectangle on Fig. 17 at higher magnification, showing numerous infoldings (I) of the funicle plasma membrane. F, funicle cell ; M, mitochondrion ; Oe, ovarian epithelial cell ; Pm, plasma membrane ; Sp, spermatozoon ; Za, zonula adherence.

Fig. 19. Electron micrograph showing the collapsed basement membrane (Bm) and the worn-out funicle cells $(\mathrm{F})$ after ovulation. $\mathrm{H}$, haemocoel. 